\title{
Mechanisms of Oxidation-Reduction Reactions Can Be Predicted by the Magnetic Isotope Effect
}

\author{
Vladimir N. Epov \\ Laboratoire de Chimie Analytique Bio-Inorganique et Environnement, \\ Institut Pluridisciplinaire de Recherche sur l'Environnement et les Matériaux, CNRS-UPPA-UMR-5254, Hélioparc, \\ 2 avenue du Président Pierre Angot, 64053 Pau, France
}

Correspondence should be addressed to Vladimir N. Epov, vladimir.epov@univ-pau.fr

Received 5 August 2011; Revised 4 October 2011; Accepted 26 October 2011

Academic Editor: Paul H. Wine

Copyright (c) 2011 Vladimir N. Epov. This is an open access article distributed under the Creative Commons Attribution License, which permits unrestricted use, distribution, and reproduction in any medium, provided the original work is properly cited.

\begin{abstract}
Magnetic isotope effect can cause mass-independent isotope fractionation, which can be used to predict the mechanisms of chemical reactions. In this critical paper, the isotope fractionation caused by magnetic isotope effect is used to understand detailed mechanisms of oxidation-reduction reactions for some previously published experimental data. Due to the rule that reactions are allowed for certain electron spin state, and forbidden for others, magnetic isotopes show chemical anomalies during these reactions due to the hyperfine interaction of the nuclear spin with the electron spin. It is demonstrated that compound or complex in paramagnetic (triplet) state accepts electrons during the reactions of electron transfer. Also, ligand field strength is responsible for the magnitude and the sign of the mass-independent fractionation. From another side, magnetic isotope effect can be used to predict the ligand strength. According to the proposed mechanism, the following parameters are important for the sign and magnitude of mass-independent isotope fractionation caused by magnetic isotope effect (due to predominant either singlettriplet or triplet-singlet evolution): (i) the arrangement of the ligands around the metal ion; (ii) the nature (strength) of the ligands surrounding the metal ion; (iii) presence/absence of light. The suggested approach is applied to understand Hg reduction by dissolved organic carbon or by $\mathrm{Sn}(\mathrm{II})$.
\end{abstract}

\section{Introduction}

Natural variations in the stable isotope composition of elements have been used by scientists to study different environmental, chemical, and biological processes. The isotope effect is a kinetic phenomenon resulting in the fractionation of nuclei, and leading to their unequal proportions in the reactants and products. Mass-dependent isotope fractionation (MDF) has been extensively studied and described in number of theoretical and experimental researches $[1,2]$. According to the nuclear-mass isotope effect, the isotope enrichment factor is proportional to the mass difference of the isotopes leading to MDF, which is directly related to the difference in the nuclear mass among the isotopes of an element.

However, in some cases, anomalous or mass-independent isotope fractionation (MIF) has been observed. Firstly, this MIF was observed for ${ }^{17} \mathrm{O}$ and ${ }^{33} \mathrm{~S}$ isotopes [3] and recently for several odd isotopes of heavy metals [4-7]. This
MIF can be attributed to one of the two following mechanisms. (1) Nuclear field shift (NFS) or by other words nuclear volume isotope effect in which the difference between the radii of the nuclei is detected. This effect was first described by Bigeleisen [8]. He has stated that the main principle of this effect is that often the nuclear volume of odd isotope is smaller than those for neighboring even isotopes. As it was reported by Schauble [9], the NFS effect causes the larger isotopes to preferentially enrich the chemical species with lower electron density at the nucleus. The magnitude of MIF produced by NFS is insignificant in comparison with MDF, and in the cases of single-stage experiments it is not detectable or poorly detectable by modern analytical techniques. However, it should be mentioned that NFS effect is also observed for even atomic mass isotopes as it was demonstrated by Knyasev and Myasoedov for ${ }^{58} \mathrm{Fe} /{ }^{54} \mathrm{Fe}$, ${ }^{104} \mathrm{Ru} /{ }^{96} \mathrm{Ru}$, and ${ }^{192} \mathrm{Os} /{ }^{188} \mathrm{Os}$ isotopic systems [10] and by Schauble for ${ }^{198} \mathrm{Hg} /{ }^{202} \mathrm{Hg}$ isotope ratio [9], whereas magnetic 
isotope effect produces isotope fractionation anomalies only for odd atomic mass of isotopes having nuclear spin.

(2) Nuclear magnetic isotope effect (MIE) [11, 12] takes place when nuclear spins and magnetic moments are responsible for isotope separation. This effect is based on the fundamental physical chemistry principle: "chemical reactions are spin selective; they are allowed for those spin states of reagents whose total electron spin is identical to that of products; hence, the reactions are forbidden if they require a change of spin" [13]. The interaction of magnetic moments of nuclei with magnetic moments of electrons provides nuclear-electronic hyperfine coupling and hence changes the electron spin state. The hyperfine interactions cause the appearance of magnetic isotope effect in chemical reactions. The magnitude of MIE can be easily detected with modern mass spectrometry, as sometimes it can reach values of MDF. Nuclear-mass effect, which causes MDF, and NFS effect, which causes MIF, exist in all reactions and at any mechanisms and has thermodynamic nature determining the equilibrium distribution of isotopes in reactions, whereas MIE is the kinetic effect and is indicative for spin-selective reactions. Hence, it is the only isotope effect that detects the mechanism of the reaction [13].

In this paper the author proposes the mechanisms of some oxidation-reduction reactions, for which high magnitude of MIF was experimentally detected. These mechanisms for few reactions are described below in detail based on MIE electron transfer and type of ligands. This is the second paper describing reaction mechanisms using MIE, as the first one described ligand exchange (or complexation) reactions [14].

\section{Discussions}

Recently, different research groups have observed massindependent isotope fractionation (MIF) of few heavy metals during their oxidation-reduction reactions. One of the first papers explaining MIF in heavy metals was the study of Bigeleisen for the ${ }^{238} \mathrm{U} /{ }^{235} \mathrm{U}$ separation in the $\mathrm{U}(\mathrm{III})-$ $\mathrm{U}(\mathrm{VI})$ and $\mathrm{U}(\mathrm{IV})-\mathrm{U}(\mathrm{VI})$ exchange reactions [8]. The author concluded that NFS is the one responsible for the MIF since hyperfine splitting is an order of magnitude too small to explain this MIF by MIE. However, in this paper, I propose that following parameters are also important for the prediction of MIE mechanism: the nature of the ligands (particularly, its strength should determine initial electron spin, i.e., singlet or triplet) and their arrangement around the metal ion (type of species and number of free orbitals). For example, U(IV) can be either in singlet or triplet electron ground state, that will depend on atomic orbitals hybridization, number, and strength of the ligands.

Mercury is the most studied heavy element which displays significant MIF during its electron transfer reactions that was reported and reviewed elsewhere [5-8, 13, 15-18]. Also, MIF was recently discovered for oxidation-reduction reaction of another couple of heavy metals, that is, for strontium (precipitation reaction of $\mathrm{SrO}_{2}$ produced from $\mathrm{Sr}^{2+}$ by hydrogen peroxide) [19] and zinc (oxidation of $\mathrm{Zn}^{0}$ to $\mathrm{Zn}^{2+}$ by $\mathrm{Cr}^{3+}$ ) [20]. For zinc [21], this MIF was very insignificant and can be attributed to the NFS. For Sr [20] the aqueous fraction $\left(\mathrm{Sr}^{2+}\right)$ was found to be enriched in lighter isotopes, that means that the following reaction is the one responsible for the classical MDF (as lighter isotopes react faster): $\mathrm{SrO}_{2}+2 \mathrm{H}_{2} \mathrm{O}^{+}+2 \overline{\mathrm{e}}=\mathrm{Sr}^{2+}+4 \mathrm{OH}^{-}$. The speed of this reaction is very slow thus, MIE should be very insignificant for this reaction. Hence, only mercury will be discussed in this paper. Schauble [9] described role of nuclear volume in driving equilibrium stable isotope fractionation of $\mathrm{Hg}$ and other heavy elements; both MDF and nuclear volume effects tend to enrich the neutron-rich isotopes in oxidized $\mathrm{Hg}$ species. The value of nuclear volume MIF significantly depends on the species and temperature: for example, for ${ }^{198} \mathrm{Hg}^{202} \mathrm{Hg}$ isotope pair, it is highest in $\mathrm{Hg}^{0}-\mathrm{Hg}^{2+}$ redox system at $298 \mathrm{~K}$ for $\mathrm{Hg}^{2+}$ species, that is, fractionation factor is equal to $3.17 \%$. For $\mathrm{Hg}^{0}-\mathrm{HgCl}_{2}$ and $\mathrm{Hg}^{0}-\mathrm{HgCl}_{4}{ }^{2-}$ species, this factor is equal to $1.27 \%$ and $2.22 \%$, respectively. It is lower for organic mercury complexes, that is, $0.57 \%$ o for $\mathrm{Hg}\left(\mathrm{CH}_{3}\right)_{2}$ and $0.80 \%$ for $\mathrm{Hg}\left(\mathrm{CH}_{3}\right) \mathrm{Cl}$, whereas maximum value of MIE was observed for the reduction of $\mathrm{Hg}^{2+}$ in the presence of dissolved organic carbon (DOC); fractionation factor is equal to $5.01 \%$ o for ${ }^{201} \mathrm{Hg}_{-}{ }^{198} \mathrm{Hg}$ isotope pair [16].

2.1. Magnetic Isotope Effect for Mercury Reduction. Blum and Berguist were the first who described MIF of mercury caused by magnetic isotope effect during oxidation of methylmercury ( $\mathrm{MeHg}$ ) and inorganic mercury ( $\mathrm{IHg}$ ) to $\mathrm{Hg}^{0}$ [15]. They demonstrated that reduction of $\mathrm{Hg}$ by dissolved organic carbon (DOC) in the presence of light leads to enrichment of initial reagents by ${ }^{199} \mathrm{Hg}$ and ${ }^{201} \mathrm{Hg}$ magnetic isotopes. Also, recently significant MIF of magnetic $\mathrm{Hg}$ isotopes was discovered in a number of environmental and biological samples $[5,6]$, that can be attributed to the above mentioned oxidation-reduction reactions. Most positive MIF was observed in food-web samples, representing $\mathrm{MeHg}^{+}$ and $\mathrm{IHg}^{2+}$ species (up to $+5 \%$ o for fish, up to $+1.8 \%$ o for plankton and up to $+1 \%$ for hair samples as $\Delta^{201} \mathrm{Hg}$ ), whereas most negative MIF was observed in atmospheric mercury representing $\mathrm{Hg}^{0}$ such as snow (down to $-5.5 \%$ o $\Delta^{201} \mathrm{Hg}$ ) and mosses with lichens (down to $-1.5 \% \Delta^{201} \mathrm{Hg}$ ).

Zheng and Hintelmann [16] have discovered that the magnitude of MIF in the presence of light is related to the ratio of $\mathrm{Hg} / \mathrm{DOC}$ concentrations in the reactants. DOC represents very complex mixture of different organic compounds composed of $\mathrm{C}, \mathrm{O}, \mathrm{N}, \mathrm{H}$, and $\mathrm{S}$ in varying proportions. The most common category of soil-derived organic material is the humic substances, defined as high molecular weight (up to several hundred thousand mass units), refractory, heterogeneous organic substances, which represents about $80 \%$ of DOC [21]. In noncontaminated groundwater, low-molecular-weight (LMW) compounds make up the remaining 20\%. The LMW DOC includes cellulose, protein, carbohydrates, carboxylic acids, amino acids, and hydrocarbons. The DOC functional groups which can participate in binding and reduction of $\mathrm{Hg}$ are summarized in Table 1. Also, possible products of these groups in ox-red reactions are presented in Table 1.

To understand the processes of $\mathrm{Hg}$ reduction in DOC, very important experimental paper was published by Zheng and Hintelmann [18]. Authors studied MDF and MIF of 
TABLE 1: Main functional groups of DOC, which create complexation binding with $\mathrm{Hg}$ and participate in oxidation-reduction reactions.

\begin{tabular}{lcc}
\hline Binding site & Functional group & Products \\
\hline Oxygen $(\mathrm{O})$ & $\mathrm{HO}-\mathrm{C}=\mathrm{O}$ & $\mathrm{CO}_{2}$ \\
& $-\mathrm{CH}_{2}-\mathrm{OH}$ & $-\mathrm{HC}=\mathrm{O}$ \\
\hline \multirow{3}{*}{ Nitrogen $(\mathrm{N})$} & $-\mathrm{CH}_{2}-\mathrm{NH}_{2}$ & \\
& $-\mathrm{CH}_{2}-\mathrm{NH}-\mathrm{CH}_{2}-$ & $\mathrm{NH}_{3}+-\mathrm{CH}_{3}$ \\
& $-\mathrm{CH}_{2}-\mathrm{N}-\mathrm{CH}_{2}-$ & \\
& $\mathrm{C}$ & \\
& $\mathrm{CH}_{2}$ & \\
\hline \multirow{2}{*}{ Sulphur (S) } & $-\mathrm{CH}_{2}-\mathrm{SH}$ & $-\mathrm{CH}_{2}-\mathrm{S}-\mathrm{S}-\mathrm{CH}_{2}-$ \\
& $-\mathrm{CH}_{2}-\mathrm{S}-\mathrm{CH}_{2}-$ & \\
\hline
\end{tabular}

mercury isotopes during its photochemical reduction by different low-molecular-weight organic compounds. Several compounds with main DOC functional groups (Table 1) had been chosen. Authors demonstrated that sulphur and nitrogen containing groups create positive MIF of ${ }^{199} \mathrm{Hg}$ and ${ }^{201} \mathrm{Hg}$ magnetic isotopes in the product, that is, $\mathrm{Hg}^{0}$, whereas in the case of oxygen-containing groups, negative MIF of $\mathrm{Hg}$ isotopes in the product was observed. Authors explained this MIF by magnetic isotope effect. Unfortunately, diagrams presented in the later paper do not give an understanding of the reaction mechanisms.

Based on the experimental results given by Zheng and Hintelmann [18], the detailed mechanisms are presented here, which can help to understand $\mathrm{Hg}$ reduction process by different functional groups of DOC. First, it should be noted that $\mathrm{Hg}^{2+}$ creates very stable and strong binding with S-containing organic compounds, due to two the following reasons [21, 22]: "Mercury is classified as a Btype metal cation, characterized by a soft sphere of highly polarisable electrons in its outer shell." Thus, as a soft acid, $\mathrm{Hg}$ shows a tendency to binding soft base S-containing thiol groups, creating "soft-soft" covalent bonds [21]. Ncontaining organic groups are also soft base and have a tendency (but less than S-containing group) to covalent binding with mercury if they have available electron pair, whereas $\mathrm{O}$-containing groups are hard bases, that makes their binding with $\mathrm{Hg}$ as intermediate between covalent and ionogenic. It is known that soft base represents a ligand of a strong field thus, $\mathrm{S}$ - and $\mathrm{N}$-organic groups are this type of ligands, and $\mathrm{O}$-containing groups are weak-field ligands. Based on this, the following mechanisms presented on Figures 1, 2 and 3 can be suggested for three different functional groups.

\subsection{Reduction of $\mathrm{Hg}$ by S-Containing Functional Groups.} Cysteine (Cys) is chosen to explain the mechanism of $\mathrm{Hg}$ reduction by S-containing organic molecule. As it was demonstrated previously [22], the molecule of cysteine is monodentately coordinated through $\mathrm{S}$ donor atom with $\mathrm{Hg}(\mathrm{Cys})_{2}{ }^{2-}$ as the predominant species. Since thiol-group is a ligand of strong field, the ground electron state of $\mathrm{Hg}$ in this species will be $[\mathrm{Xe}] 4 \mathrm{f}^{14} 5 \mathrm{~d}^{10}$ singlet ${ }^{1} \mathrm{~S}_{0}$ with two 6 sp hybrid orbitals (see Figure 1) .
Singlet electron state can undergo singlet-triplet spin evolution due to photochemical excitation, which is faster for ${ }^{199} \mathrm{Hg}$ and ${ }^{201} \mathrm{Hg}$ magnetic isotopes due to hyperfine coupling between magnetic nucleus and electrons. Also, this spin evolution from diamagnetic to paramagnetic state is faster in the presence of light. Thus, mercury changes its orbital hybridisation from $s p$-linear to $d s p^{2}$-planar square. According to this mechanism of the reaction, triplet state of $\mathrm{Hg}$ has more tendencies to reduction than singlet state due to the electron transfer from sulphur to mercury. As a result of the reaction the following products are produced: $\mathrm{Hg}^{0}$, Cystine and two protons $\left(\mathrm{H}^{+}\right)$. Elemental mercury produced in this reaction is enriched by magnetic mercury isotopes because of MIE-MIF and by lighter isotopes because of MDF.

During experimental study of later reaction, Zheng and Hintelmann have also observed that MIF becomes very insignificant in the product $\mathrm{Hg}^{0}$, if the concentration of mercury in the solution becomes very low. This fact can be explained by the participation of all valent $6 \mathrm{sp}^{3} \mathrm{Hg}$ orbitals in the binding with the molecules of cysteine. Thus, there is less possibility to change the spin state from singlet to triplet one. Probably, singlet state $\mathrm{Hg}^{2+}$ undergoes reduction much slower that is in agreement with the kinetics of the process presented elsewhere [18].

\subsection{Reduction of $\mathrm{Hg}$ by N-Containing Functional Groups.} LMW organic compounds with nitrogen-containing functional group also can produce "soft-soft" covalent bond with $\mathrm{Hg}^{2+}$ if free electron pair of nitrogen is available. $\mathrm{N}$-containing group is a ligand of strong field, and its complex with $\mathrm{Hg}$ should have singlet electron ground state. Typical example of this molecule is ethylenediamine. Its reaction with $\mathrm{Hg}$ was studied experimentally, and mercury demonstrated positive MIF of magnetic ${ }^{199} \mathrm{Hg}$ and ${ }^{201} \mathrm{Hg}$ isotopes in the product of the reaction $\mathrm{Hg}^{0}$ [18]. The mechanism of the reaction is similar to that presented above for cysteine: (i) initially bidentate complex (see Figure 2) of ethylenediamine with $\mathrm{Hg}$ has singlet electron ground state; (ii) it can undergo singlet-triplet spin evolution due to photochemical excitation, which is faster for magnetic $\mathrm{Hg}$ isotopes; (iii) the triplet state $\mathrm{Hg}$ can accept two electrons from $\mathrm{N}$-containing functional group producing elemental mercury; (iv) whereas ethylenediamine is oxidised to $\mathrm{N}_{2}$ and $\mathrm{CH}_{3}-\mathrm{CH}_{3}$. This mechanism is in agreement with experimental results of Zheng and Hintelmann [18].

\subsection{Reduction of $\mathrm{Hg}$ by O-Containing Functional Groups.} Several ligands that create binding through O-containing groups, that is, $-\mathrm{COO}^{-}$or $-\mathrm{CH}_{2}-\mathrm{OH}$, have been also experimentally studied for their influence on isotopic fractionation during reaction with $\mathrm{Hg}^{2+}$. O-containing groups represent strong base [23], and thus a ligand of a weak field. Mercury (with coordination number two) creates binding with oxygen in the absence of S-containing groups in the molecule. Thus, complexes of $\mathrm{Hg}$ with $\mathrm{O}$-containing groups should have triplet ground electron state in the presence of light (see Figure 3 as an example of oxalic acid).

Triplet state mercury complex can either undergo tripletsinglet evolution (direction of the reaction (i)), which is 


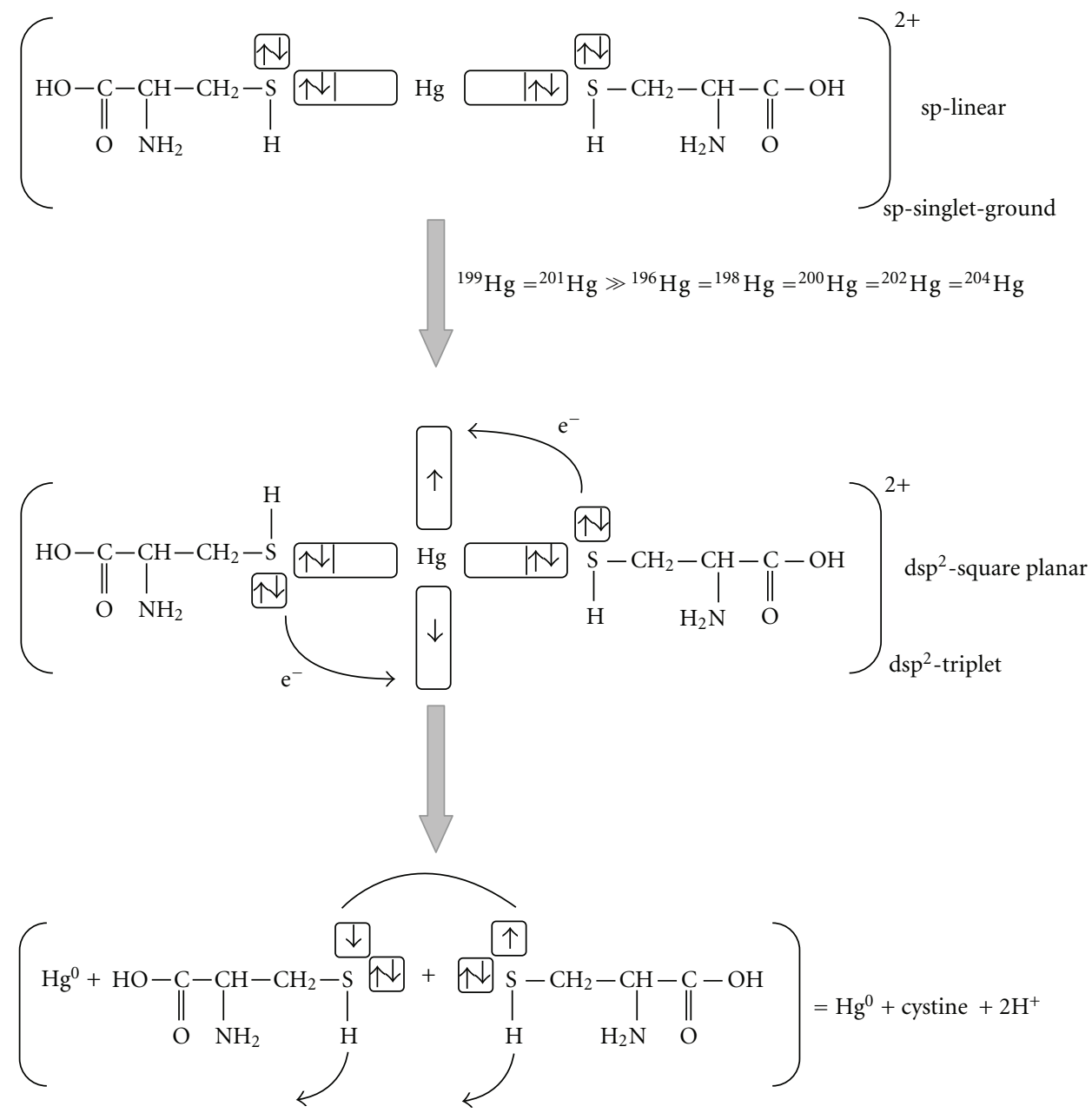

FIGURE 1

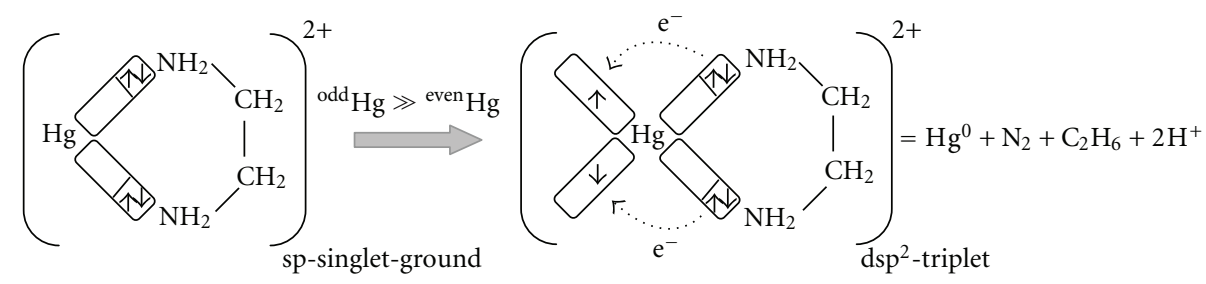

Figure 2

more rapid for magnetic mercury isotopes, that is, ${ }^{199} \mathrm{Hg}$ and ${ }^{201} \mathrm{Hg}$, or reduce mercury to $\mathrm{Hg}^{0}$ (direction of the reaction (ii) on the scheme). As singlet state complex has less probability to participate in the electron transfer reaction, the product of the reaction, that is, $\mathrm{Hg}^{0}$, becomes depleted in magnetic ${ }^{199} \mathrm{Hg}$ and ${ }^{201} \mathrm{Hg}$ isotopes. The later is in agreement with experimental results [18].

2.5. Influence of the Ligand Strength on the Extent of MIF. According to the recently published paper [14], the magnitude of the MIF should depend on the strength of the ligand field. As it was demonstrated in previous sections, paramagnetic complexes are more responsible for the electron transfer in oxidation-reduction reactions. Thus, it can be concluded that the ligand producing the most positive MIF in the $\mathrm{Hg}^{0}$ product is supposed to have the strongest field, since the magnitude of MIF should demonstrate the difference in singlet-triplet spin evolution for magnetic and nonmagnetic isotopes. The ligand producing the most negative MIF in the product is supposed to have the weakest field. Zheng and Hintelmann [18] experimentally observed significant difference in the MIF $\Delta$-values for different LMW compounds. According to their results, the studied ligands can be located from the strongest to the weakest one in the order presented in Figure 4 (based on the $\Delta$-values for the product). Binding sites are allocated by circles. From one side, this position of ligands is in good agreement with the previously published for some ligands, that is, for oxalic 


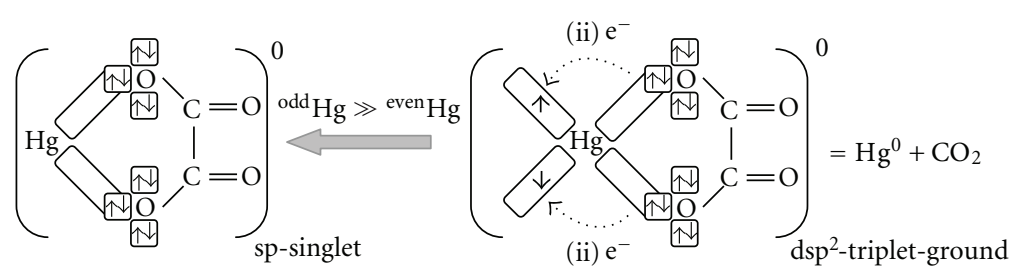

FIgURe 3

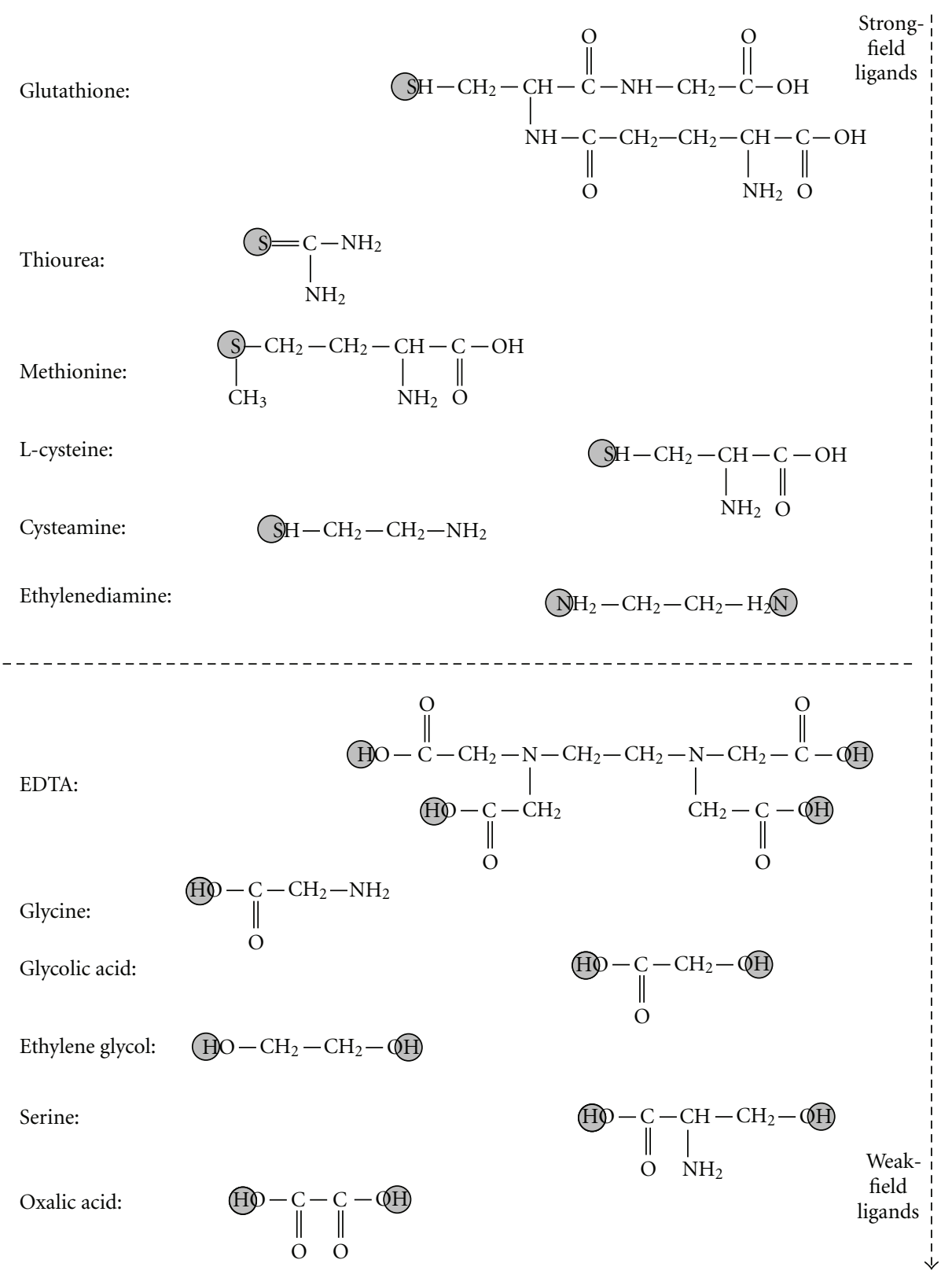

FIgURe 4

acid and ethylenediamine [23]. From another side, the MIEMIF can be used to predict the ligand strength as for other ligands this order in agreement with their strength. For example, glutathione demonstrates the strongest field from the studied S-containing ligands, which is logically explained by the presence of maximum number of the $\mathrm{N}$ - and $\mathrm{O}$ containing functional groups making the $\mathrm{S}$-containing group softer base. On the other hand, cysteamine with only one additional $\mathrm{N}$-containing group has the weakest field among the studied S-containing ligands. 
TABLE 2: Kinetics of the Hg photoreduction and its MDF and MIF isotope fractionation dependent on the Hg/DOC ratio.

\begin{tabular}{lccc}
\hline $\mathrm{Hg} / \mathrm{DOC}(\mathrm{ng} / \mathrm{mg})$ & \multicolumn{2}{c}{$\begin{array}{c}\text { Fo of Hg reacted during the } \\
\text { first hour }\end{array}$} & $\begin{array}{c}\text { for }{ }^{200} \mathrm{Hg} /{ }^{198} \mathrm{Hg}(\mathrm{MDF}) \\
\mathrm{For}{ }^{201} \mathrm{Hg} /{ }^{198} \mathrm{Hg}(\mathrm{MIF})\end{array}$ \\
\hline 34.6 & $5 \%$ & 0.36 & 2.73 \\
167 & $8 \%$ & 0.28 & 4.07 \\
833 & $10 \%$ & 0.53 & 5.01 \\
8330 & $50 \%$ & 0.50 & 2.21 \\
\hline
\end{tabular}

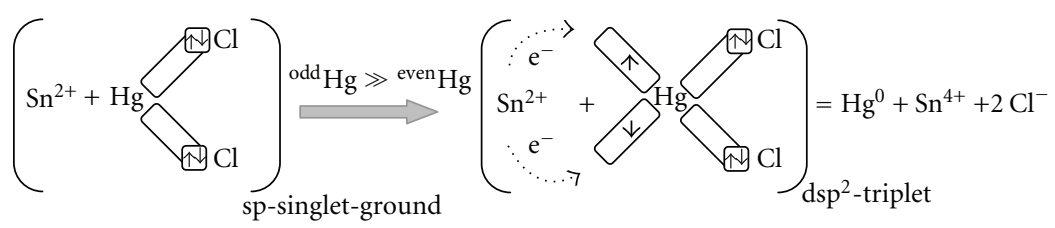

FIGURE 5

Though DOC contains all the above discussed functional groups, according to the review of Ravichandran [21], Scontaining groups are minor constituents of DOC, ranging from about 0.5 to $2 \%$ by weight. According to the previously published results $[15,16]$, reduction of $\mathrm{Hg}$ and $\mathrm{MeHg}$ by DOC in the presence of light produces negative MIF in the products. Though $\mathrm{Hg}$ is expected to preferentially bind with thiol and other S-containing groups, the sign of MIF for mercury reduction demonstrates that it is produced by $\mathrm{O}$ containing groups, which are the major groups in DOC.

Also Zheng and Hintelmann [16] demonstrated that the magnitude of the MIF is dependent on the $\mathrm{Hg} / \mathrm{DOC}$ ratio, that is, MIF is moderate at low ratio $\left(34.6 \mathrm{ng} \mathrm{mg}^{-1}\right)$, increasing with higher $\mathrm{Hg}$ concentration ( $833 \mathrm{ng} \mathrm{mg}^{-1}$ ), and than decreasing again with highest concentration $\left(8330 \mathrm{ng} \mathrm{mg}^{-1}\right)$. This can be also explained by the mechanisms presented in this paper. When concentration of $\mathrm{Hg}$ is lower, the ratio of S-bindings/O-bindings with $\mathrm{Hg}$ is higher, and the ratio of electron ground states of complexes singlet/triplet is also higher, which can cause less positive MIF. With the increase of $\mathrm{Hg}$ concentration, singlet/triplet ground states ratio is decreasing, and MIF becomes more positive. At very high $\mathrm{Hg}$ concentration, the reduction of $\mathrm{Hg}$ becomes very rapid (the amount of $\mathrm{Hg}$ reacted during first hour is presented in Table 2), and triplet-singlet evolution of the electron spin happens for the fewer amounts of $\mathrm{Hg}$ atoms (MIF of ${ }^{201} \mathrm{Hg}$ presented in Table 2 as fractionation factor is lower for higher Hg concentration) [16].

2.6. Influence of Light-Dark Conditions on the Sign of MIF. Another paper published by Zheng and Hintelmann [17] demonstrates that in dark conditions with DOC, mercury showed opposite sign of the MIF, which is positive in the products. Authors attributed these results to the MIF caused by nuclear volume. However, the magnitude of the observed MIF is quite high, and MIF was observed only for odd isotopes (whereas Schauble [9] demonstrated that nuclear volume effect is also important for even isotopes of mercury). Thus, I can explain this MIF by the MIE using mechanisms described above: (i) initial ground state of $\mathrm{Hg}$-complexes with $\mathrm{O}$-containing ligands in dark conditions is diamagnetic singlet one; (ii) the complex can undergo singlet-triplet spin evolution, which is more rapid for ${ }^{199} \mathrm{Hg}$ and ${ }^{201} \mathrm{Hg}$ isotopes; (iii) triplet state is the one which is responsible for the reduction of $\mathrm{Hg}$.

Also, in the later paper, authors observed the positive MIF in the product $\left(\mathrm{Hg}^{0}\right)$ of oxidation-reduction reaction: $\mathrm{Hg}^{2+}+\mathrm{Sn}^{2+}=\mathrm{Hg}^{0}+\mathrm{Sn}^{4+}$. Based on the experimental results presented by the authors and MIE, the proposed mechanism of this reaction is presented in Figure 5.

In the absence of light, the ground electron state of $\mathrm{Hg}$ is the singlet one. This ground state can undergo singlet-triplet evolution, which is more rapid for ${ }^{199} \mathrm{Hg}$ and ${ }^{201} \mathrm{Hg}$ magnetic isotopes. Triplet state is the one which is responsible for the reaction of electron transfer, producing the products of the reaction, that is, $\mathrm{Hg}^{0}$ and $\mathrm{Sn}^{4+}$.

\section{Conclusions}

Oxidation-reduction reaction mechanisms were explained using magnetic isotope effect during reduction of $\mathrm{Hg}$. Magnetic isotopes fractionate differently from nonmagnetic ones, due to the different rate of the electron spin state evolution. It was demonstrated that MIF caused by MIE can help to estimate the ligand field strength, which is in agreement with some previously published ligands in spectrochemical series. Also, it was shown that it is rather paramagnetic than diamagnetic electron spin state which tends to accept electrons during reduction. The magnitude and the sign of the MIE-MIF in the reactions depend on the presence of light, ligand type, and strength.

\section{Acknowledgments}

The author would like to acknowledge Institut National des Sciences de l'Univers for the financial support. He thanks two anonymous referees for the valuable comments that helped to improve the paper. 


\section{References}

[1] J. Hoefs, Stable Isotope Geochemistry, Springer, Berlin, Germany, 6th edition, 2009.

[2] M. Wolfsberg, W. A. Van Hook, and P. Paneth, Isotope Effects in the Chemical, Geological, and Bio Sciences, Springer, Dordrecht, The Netherlands, 2010.

[3] M. H. Thiemens, "History and applications of mass-independent isotope effects," Annual Review of Earth and Planetary Sciences, vol. 34, pp. 217-262, 2006.

[4] T. Fujii, F. Moynier, and F. Albarède, "The nuclear field shift effect in chemical exchange reactions," Chemical Geology, vol. 267, no. 3-4, pp. 139-156, 2009.

[5] B. A. Bergquist and J. D. Blum, "The odds and evens of mercury isotopes: applications of mass-dependent and massindependent isotope fractionation," Elements, vol. 5, no. 6, pp. 353-357, 2009.

[6] V. N. Epov, D. Malinovskiy, F. Vanhaecke, D. Bégué, and O. F.X. Donard, "Modern mass spectrometry for studying mass-independent fractionation of heavy stable isotopes in environmental and biological sciences," Journal of Analytical Atomic Spectrometry, vol. 26, no. 6, pp. 1142-1156, 2011.

[7] D. Malinovsky and F. Vanhaecke, "Mass-independent isotope fractionation of heavy elements measured by MC-ICPMS: a unique probe in environmental sciences," Analytical and Bioanalytical Chemistry, vol. 400, no. 6, pp. 1619-1624, 2011.

[8] J. Bigeleisen, "Nuclear size and shape effects in chemical reactions. Isotope chemistry of the heavy elements," Journal of the American Chemical Society, vol. 118, no. 15, pp. 36763680, 1996.

[9] E. A. Schauble, "Role of nuclear volume in driving equilibrium stable isotope fractionation of mercury, thallium, and other very heavy elements," Geochimica et Cosmochimica Acta, vol. 71, no. 9, pp. 2170-2189, 2007.

[10] D. A. Knyazev and N. F. Myasoedov, "Specific effects of heavy nuclei in chemical equilibrium," Separation Science and Technology, vol. 36, no. 8-9, pp. 1677-1696, 2001.

[11] A. L. Buchachenko, "Magnetic effects in chemical reactions," Russian Chemical Reviews, vol. 45, no. 5, pp. 375-390, 1976.

[12] N. J. Turro, "Influence of nuclear spin on chemical reactions: magnetic isotope and magnetic," Proceedings of the National Academy of Sciences of the United States of America, vol. 80, no. 2, pp. 609-662, 1983.

[13] A. Buchachenko, "Mercury isotope effects in the environmental chemistry and biochemistry of mercury-containing compounds," Russian Chemical Reviews, vol. 78, no. 4, pp. 319-328, 2009.

[14] V. N. Epov, "Magnetic isotope effect and theory of atomic orbital hybridization to predict a mechanism of chemical exchange reactions," Physical Chemistry Chemical Physics, vol. 13, no. 29, pp. 13222-13231, 2011.

[15] B. A. Bergquist and J. D. Blum, "Mass-dependent and independent fractionation of $\mathrm{Hg}$ isotopes by photoreduction in aquatic systems," Science, vol. 318, no. 5849, pp. 417-420, 2007.

[16] W. Zheng and H. Hintelmann, "Mercury isotope fractionation during photoreduction in natural water is controlled by its Hg/DOC ratio," Geochimica et Cosmochimica Acta, vol. 73, no. 22, pp. 6704-6715, 2009.

[17] W. Zheng and H. Hintelmann, "Nuclear field shift effect in isotope fractionation of mercury during abiotic reduction in the absence of light," Journal of Physical Chemistry A, vol. 114, no. 12, pp. 4238-4245, 2010.
[18] W. Zheng and H. Hintelmann, "Isotope fractionation of mercury during its photochemical reduction by low-molecularweight organic compounds," Journal of Physical Chemistry A, vol. 114, no. 12, pp. 4246-4253, 2010.

[19] T. Fujii, S. Fukutani, and H. Yamana, "Isotope fractionation of strontium in a precipitation reaction of $\mathrm{SrO}_{2}$," Journal of Nuclear Science and Technology, supplement 6, pp. 15-18, 2008.

[20] T. Fujii, F. Moynier, A. Uehara et al., "Mass-dependent and mass-independent isotope effects of zinc in a redox reaction," Journal of Physical Chemistry A, vol. 113, no. 44, pp. 1222512232, 2009.

[21] M. Ravichandran, "Interactions between mercury and dissolved organic matter-a review," Chemosphere, vol. 55, no. 3, pp. 319-331, 2004.

[22] D. F. Pyreu, A. M. Ryzhakov, E. V. Kozlovskii, M. S. Gruzdev, and R. S. Kumeev, "Mixed-ligand complex formation of mercury (II) ethylenediaminetetraacetate with cysteine and methionine in aqueous solution," Inorganica Chimica Acta, vol. 371, no. 1, pp. 53-58, 2011.

[23] H. L. Schläfer and G. Gliemann, Basic Principles of Ligand Field Theory, Wiley Interscience, New York, NY, USA, 1969. 


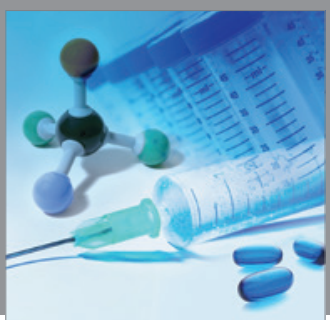

International Journal of

Medicinal Chemistry

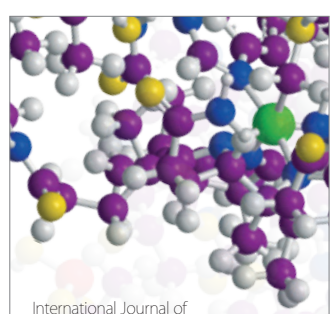

Carbohydrate Chemistry

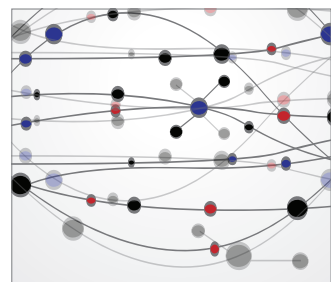

The Scientific World Journal
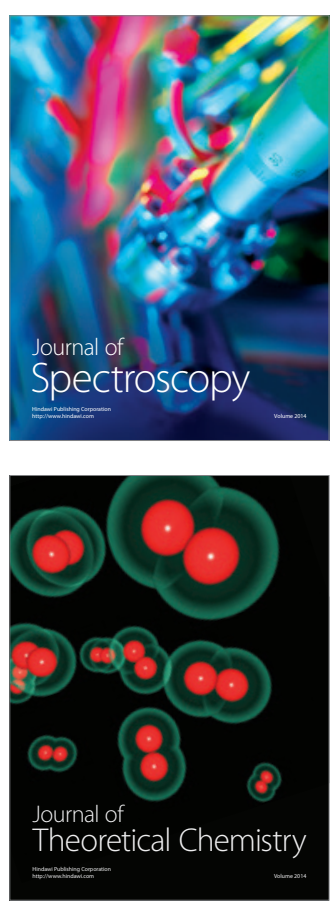
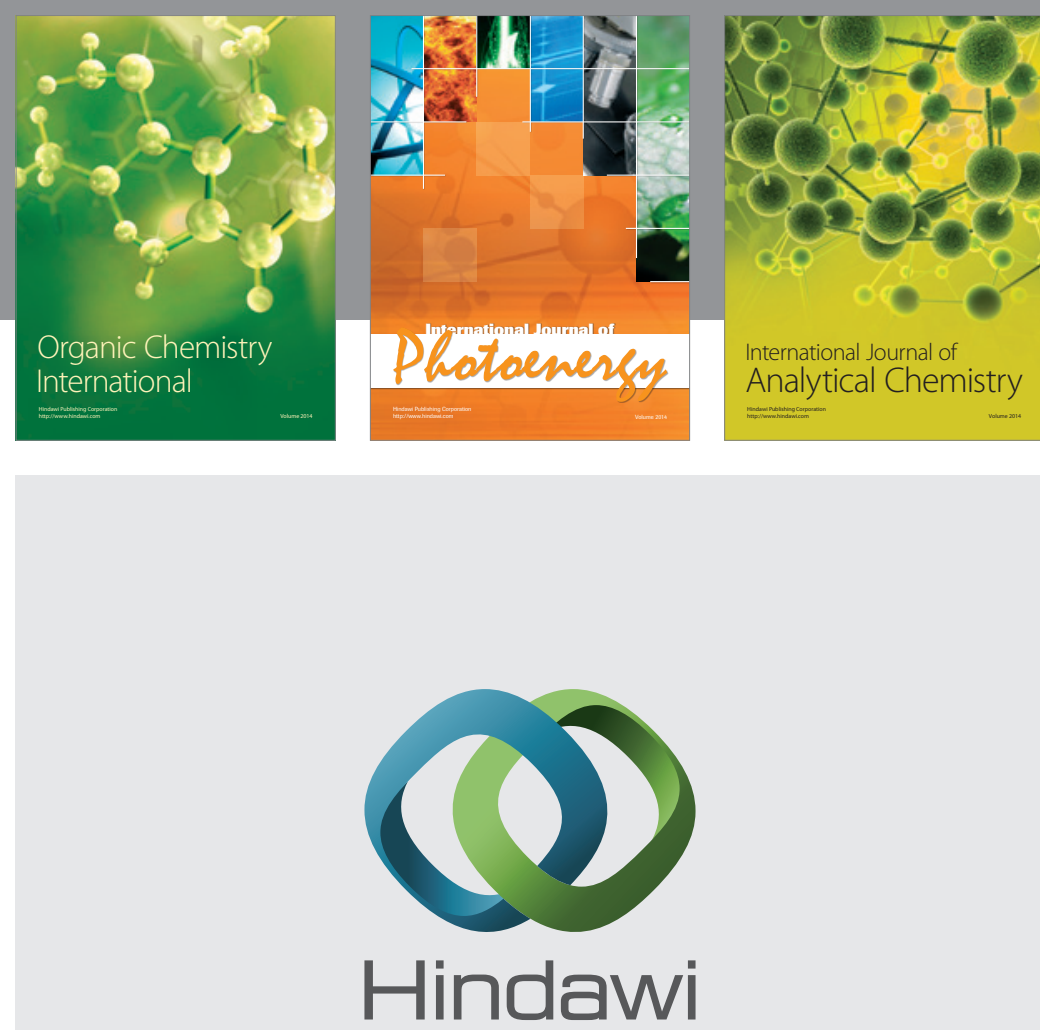

Submit your manuscripts at

http://www.hindawi.com
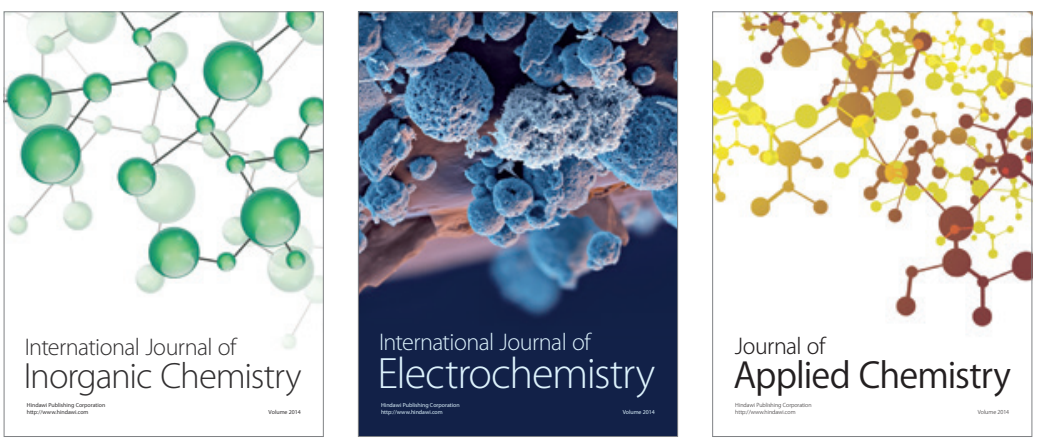

Journal of

Applied Chemistry
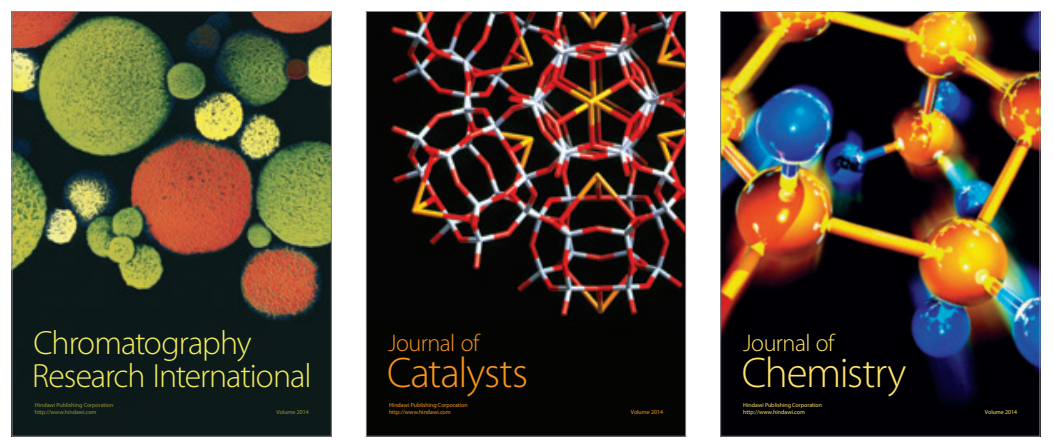
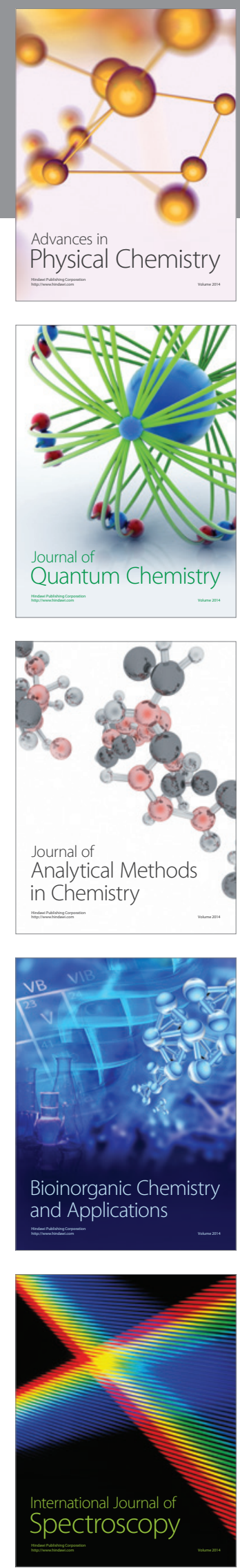